\title{
Reflexões sobre o contexto institucional brasileiro contemporâneo e as transformações na educação profissional
}

\section{Reflections on the contemporary institutional Brazilian context and the changes in professional education}

\author{
Márcio Jacometti*
}

\begin{abstract}
RESUMO
O objetivo deste artigo é propor pesquisas que verifiquem como o contexto institucional brasileiro vem afetando as transformações ocorridas no ensino profissionalizante, a partir de 1964. Trata-se de um ensaio teórico que recomenda a pesquisa histórica, de caráter descritivo. A contextualização dos fatos permite interpretar e compor o cenário das transformações da educação profissional, no período em análise. A relação de influência entre o contexto institucional e as transformações ocorridas na educação profissional brasileira pode ser verificada mediante análise qualitativa que utilize mapeamentos de relação a serem gerados por análise documental. Os resultados a serem obtidos permitirão confirmar ou refutar as hipóteses de que os contextos institucionais e os valores disseminados, por ocasião do sancionamento das duas LDBs consideradas: 1971 e 1996, não se diferenciam e caracterizam-se como neoliberais e que as pressões contextuais coercitivas e normativas vêm afetando significativamente as transformações ocorridas na educação profissional brasileira. A investigação destas hipóteses propiciará um estudo relevante e ampliará a compreensão dos rumos determinados para a educação profissional e suas conseqüências ao longo do tempo, possibilitando, inclusive, uma projeção futura, face à tendência de manutenção e homogeneização dos valores legitimados na sociedade brasileira mediante mecanismos de dominação eficazes.
\end{abstract}

* Mestre em Administração pela UFPR, professor da UTFPR - Campus Cornélio Procópio, e-mail: mjacometti@cp.cefetpr.br 
Palavras-chave: educação profissional; contexto institucional; legislação educacional.

\begin{abstract}
The objective of this article is to consider research that verifies how the Brazilian institutional context has affected the occurred transformations in professionalizing education, since 1964. One is about a theoretical essay that recommends the historical research, of descriptive character. The contextualization of the facts allows us to interpret and to compose the scene of the transformations of the professional education, in the period of analysis. The relation of influence between the institutional context and the occurred transformations in the Brazilian professional education can be verified by means of qualitative analysis that uses relation mappings to be generated for documentary analysis. The results to be gotten will allow us to confirm or to refute the hypotheses that the institutional contexts and the spread values, for occasion of considered the two promulgation of LDBs: 1971 and 1996. They are not differentiated and they are characterized as neoliberal and the coercitive and normative contextual pressures have significantly affected the occurred transformations in the Brazilian professional education. The inquiry of these hypotheses will propitiate an excellent study and will extend the understanding of the routes determined for the professional education and its consequences throughout time, making also possible, a future projection, facing the maintenance trend and homogenization of the legitimated values in the Brazilian society by means of efficient mechanisms of domination.
\end{abstract}

Keywords: professional education; institutional context; educational legislation.

\title{
Introdução
}

De acordo com Richardson et al. (1999, p. 248), “[...] existe uma grande necessidade de estudos sobre as idéias e movimentos que influenciam no desenvolvimento educacional do Brasil". No que se refere à educação profissional, esta tem se caracterizado menos como possibilidade de ascensão social para a classe trabalhadora do que suporte para o acúmulo de capital e enriquecimento das elites. 
Segundo Mendes (1998), o processo educacional brasileiro não pôde ser problematizado, sobretudo depois do Movimento de 64, e deve ser esclarecido. Os problemas se revestiam de forma especulativa e abstrata ou de uma forma caracterizada pela legislação e normas do Estado. As elites do Estado e classes dominantes se pretendem concretas sob o amparo das categorias eficiência, racionalidade e modernização. E, para fazê-las operar, é preciso mecanismo de alienação, com ramificações econômicas, culturais e políticas, além da falácia tecnocrática ${ }^{1}$.

Portanto, este estudo é de extrema importância no que tange à delimitação de novos direcionamentos para ampliar a compreensão das transformações dos processos educacionais, além de revelar, sob uma perspectiva histórica, como se articula o processo de institucionalização dos valores e normas na sociedade brasileira contemporânea. $\mathrm{O}$ ensino profissionalizante está contido nesse contexto falacioso que opera em nosso país, desde o início do Século XX.

É de supor-se, portanto, que as pressões contextuais institucionalizadas na sociedade vêm afetando as transformações do ensino profissional desde a sua implementação no país, sendo uma situação recorrente e que merece ser investigada. As regras culturais e institucionais definem e modelam as estruturas sociais (WEBER, 1944). Além disso, é de interesse dos educadores em geral conhecer, no espaço temporal demarcado, como atuaram as forças institucionais na defesa de interesses de uma minoria dominante e que têm obtido tanto êxito na reprodução dessa realidade ao longo de nossa história.

\section{O ensino profissionalizante no Brasil}

No Brasil, o ensino profissionalizante vem sendo uma preocupação dos governos desde o início do Século XX, quando, em 1909, o então Presidente

1 "O impulso tecnológico estimulou a ideologia dos meios, e o uso inebriante destes passa a substituir e mascarar a filosofia dos fins". Trata-se de mais uma cilada da alienação, que pretende fazer crer que os meios isolados dos fins se afirmam exclusivamente em virtude de sua "tecnicalidade", e os especialistas em política dos meios poderiam ser utilizados para realizar qualquer empreendimento na política dos fins" (MENDES apud HORTA, 1998, p 224) (grifos no original). Outra característica básica da tecnocracia é "a negação da dimensão política, pela absolutização dos critérios da racionalidade técnica na condução do processo decisório. [...] Partindo da afirmação de uma total independência com relação ao político, o tecnocrata acaba por negar a dimensão política, tornando assim patente a sua tendência antidemocrática, que o leva a desprezar a via democrática de legitimação do poder e a buscar esta legitimação em uma forma particular de saber, isto é o saber técnico-científico" (HORTA, 1998, p. 225). 
da República, Nilo Peçanha, criou, nas capitais dos Estados, as Escolas de Aprendizes Artífices para o ensino profissional primário e gratuito. Na época, a intenção era oferecer uma alternativa para que os filhos da classe trabalhadora adquirissem uma profissão e entrassem no mercado de trabalho.

De acordo com Queluz (2000), a abolição da escravidão, o crescimento econômico brasileiro, a industrialização e a imigração proporcionaram um crescimento acentuado e desordenado das principais cidades brasileiras. Tornava-se fundamental, como estratégia de autopreservação da burguesia do início do século XX, a imposição de uma identidade social ao proletariado emergente. Na época, a intenção era oferecer uma alternativa para que os filhos da classe trabalhadora adquirissem uma profissão e entrassem no mercado de trabalho (FONSECA, 1961). O Decreto $n^{\circ} .7 .566$, de 23 de setembro de 1909, retrata claramente, em seu preâmbulo ${ }^{2}$, a discriminação existente na sociedade brasileira da época com relação ao trabalho das oficinas, associada à necessidade de qualificação de mão-de-obra para a crescente industrialização do país (BRASIL, 1961).

Até os anos 1950, as escolas técnicas voltaram-se, portanto, para atender as necessidades da indústria incipiente. Essas escolas foram evoluindo e incorporaram o $2 .^{\circ}$ Grau profissionalizante a partir da lei n. ${ }^{\circ} 5.692 / 71$ (BRASIL, 1971).

A lei $\mathrm{n}^{\circ}$. 5.692/71 obrigou todas as instituições de $2^{\circ}$. Grau a ofertarem o curso profissionalizante integrado. Assim, muitas escolas incluíram em seus currículos disciplinas que atendiam àquela exigência. Proliferaram cursos técnicos baratos como: Contabilidade, Magistério, Administração e Secretariado, formando diversos jovens para um mercado que não existia. As Escolas Técnicas Federais, por sua vez, passaram a facilitar o acesso da classe média à universidade, enquanto a rede estadual de ensino ofertava um curso profissionalizante fraco e desvinculado da realidade do mercado de trabalho.

Dessa forma, as vagas das escolas técnicas passaram a ser disputadas pela classe média, que via naqueles estabelecimentos uma oportunidade de curso médio gratuito, de elevado nível de qualidade e que abria as portas para a universidade. A qualificação profissional que era oferecida paralelamente, conforme definido pela lei 5.692/71, não era considerada relevante, a tal ponto que muitos de seus ex-alunos cursaram medicina, direito e outros cursos superiores

2 Considerando: que o aumento constante da população das cidades exige que se facilite às classes proletárias os meios de vencer as dificuldades crescentes da luta pela existência, que para isso se torna necessário, não só habilitar os filhos dos desfavorecidos da fortuna com o indispensável preparo técnico e intelectual, como fazê-los adquirir hábitos de trabalho profícuo, que os afastará da ociosidade, escola do vício e do crime; que é um dos primeiros deveres do Governo da República formar cidadãos úteis à Nação (FONSECA, 1961, p. 163). 
sem nenhuma relação com a área técnica. Entre $60 \%$ a $70 \%$ dos egressos das Escolas Técnicas Federais, que custavam ao Governo US\$ 4 mil por aluno/ano, contra US\$ 750 por aluno/ano de outros cursos de nível médio, prosseguiam seus estudos em universidades (REVISTA, 1998).

Ribeiro (1984) considera a lei 5.692/71 “demagógica”, já que estendeu de quatro para oito anos a obrigatoriedade do ensino fundamental sem oferecer recursos, e, além disso, sobrecarregou-o com novas exigências. $\mathrm{O}$ autor explica o atraso educacional do país pelo desinteresse da classe dominante brasileira, descendente de "antigos senhores de escravos", que olha o povo como o que há de mais reles, atribuindo a ele a culpa do próprio atraso.

A implementação da lei 5.692/71 vem da arbitrariedade do Governo Militar e suas circunstâncias merecem ser investigadas. Segundo Gadotti (1991), o período pós-64 deve ser considerado um retrocesso sob muitos aspectos, não apenas pelo tecnicismo de suas propostas, mas por ter rompido com as buscas metodológicas da Escola Nova3 . "O caráter fundamental da escola do período ditatorial é o autoritarismo, o elitismo e o descaso pela formação popular. O golpe militar foi um golpe " [...] contra a ascensão crescente da classe trabalhadora ao poder, aberta com a aliança policlassista existente no período histórico anterior (o período populista: 1930-64)" (GADOTTI, 1991, p. 105).

Que fatores contextuais institucionais vieram a culminar com a imposição da lei 5.692/71? A prática de um discurso autoritário que se manteve ao longo das décadas de 1980 e 1990 foi tão eficaz na determinação das ações educacionais que essa lei somente foi revogada no final de 1996 pela nova LDB, apesar da transição política democrática no país ter se iniciado bem antes na década de 1980.

Essas considerações remetem ao discurso em Foucault (1997) que é permeado de sutilezas, não só no aspecto direto como também nas "palavras não ditas" do ato comunicativo. $\mathrm{O}$ autor evoca todos os processos conscientes do homem sem, contudo, esquecer a imensidão do inconsciente como fator de geração dos atos humanos e, conseqüentemente, do ato discursivo. Mediante uma análise dos conjuntos discursivos, pode-se encontrar o real sentido e as motivações

3 No Brasil, o movimento da Escola Nova começou na década de 20, com diversas reformas do ensino público que permaneceram esparsas. A Escola Nova representa um esforço no sentido da superação da pedagogia da essência pela pedagogia da existência. Não se trata mais de submeter o homem a valores e dogmas tradicionais, nem procurar educá-lo para a realização de sua “essência verdadeira". A pedagogia da existência se acha voltada para a problemática do indivíduo único, diferenciado, interagindo com um mundo dinâmico. No entanto, a Escola Nova é liberal na medida em que está convencida de que a verdadeira democracia poderia ser instaurada a partir da "escola redentora": todos poderiam garantir "seu lugar ao sol" a partir dos seus talentos e esforços (ARANHA, 1989). 
que levam à adoção de um discurso específico, perfeitamente possível de ser classificado de acordo com ideologias específicas de interesse comum de alguns grupos ou particularidades convenientes para o emissor atingir seus objetivos.

Os ventos da democratização, do início dos anos 80, alimentaram insondáveis esperanças. Algumas figuras expressivas do pensamento educacional progressista dedicaram-se a experiências de gestão de redes escolares em várias partes do país e alarmaram-se com o que encontraram internamente. $\mathrm{O}$ resultado que se seguiu foi, sem dúvida, desanimador. Tendências anteriores não foram revertidas e mesmo, em alguns casos, agravaram-se (COSTA, 1995, p. 46).

Da mesma forma, qual foi o discurso de que se utilizou o Estado para a aprovação da lei no . 9.394/96? Mediante essa lei, o Ministério da Educação iniciou a implementação da Reforma da Educação Profissional. Com o Decreto $n^{\circ}$. 2.208/97, desvinculou-se o antigo $2^{\circ}$. Grau da educação profissional.

Desde então, o ensino médio passou a fazer parte da Educação Básica e a Educação Profissional passou a ser um ensino pós-secundário com três níveis de formação: básico, técnico e tecnológico. Agora, quem pretende ingressar no mercado de trabalho com uma formação profissional de nível técnico deve, além de concluir o ensino médio, cursar o ensino profissional (BRASIL, 1997a; MINISTÉRIO, 2002).

Porém, o Decreto $\mathrm{n}^{\circ}$. 5.154/04 voltou a permitir o modelo integrado de curso técnico com o ensino médio (BRASIL, 2004).

Os três níveis de formação profissional foram definidos pelo art. $3^{\circ}$. do Decreto $\mathrm{n}^{\circ}$. 2.208/97, conforme segue:

- básico: destinado a trabalhadores jovens e adultos, independentemente de escolaridade prévia, tendo por objetivo a requalificação profissional, não requerendo regulamentação curricular dos cursos;

- técnico: destinado a jovens e adultos que estejam cursando ou tenham concluído o ensino médio, com o objetivo de proporcionar habilitação profissional; 
- tecnológico: corresponde a cursos de nível superior na área tecnológica, destinados a egressos do ensino médio e técnico (BRASIL, 1997b).

Segundo o Ministro da Educação do Governo Fernando Henrique, Paulo Renato Souza, o modelo de ensino técnico adotado no Brasil beneficiava as classes médias e altas e tinha um gasto social elevado. Em 1997, o ensino técnico tinha cerca de 100 mil alunos no Brasil e, dos alunos formados, metade ia para o mercado de trabalho e a outra metade para as universidades. "É uma educação de luxo para o aluno prestar o vestibular", disse o Ministro Benatti (BENATTI, 1997). A Portaria $n^{\circ} .646 / 97$ regulamentou o parágrafo $2^{\circ}$. do artigo 36 e os artigos 39 a 42 da lei $n^{\circ}$. 9.394/964 sobre a Educação Profissional e determinou que as instituições envolvidas com essa modalidade de ensino deveriam apresentar um Plano de Implantação, levando-se em conta suas condições materiais, financeiras e de recursos humanos; com o objetivo de incrementar as matrículas na educação profissional, mediante a oferta de cursos de nível técnico, desenvolvidos concomitantemente com o ensino médio, para alunos oriundos de escolas dos sistemas de ensino fundamental; cursos de nível técnico destinados a egressos de nível médio, por via regular ou supletiva; cursos de especialização e aperfeiçoamento para egressos de cursos de nível técnico e cursos de qualificação, requalificação, reprofissionalização de jovens, adultos e trabalhadores em geral, com qualquer nível de escolarização (BRASIL, 1997c).

A intenção de implementar a Reforma da Educação Profissional já havia sido sinalizada com a lei $n^{\circ}$. 8.948/94, que instituiu o Sistema Nacional de Educação Tecnológica, com a finalidade de permitir melhor articulação da Educação Tecnológica em seus vários níveis, entre suas diversas instituições, entre estas e as demais incluídas na Política Nacional de Educação, visando ao aprimoramento do ensino, da extensão, da pesquisa tecnológica, além de sua

4 Os artigos mencionados definiram que a educação profissional deveria estar integrada às diferentes formas de educação, ao trabalho, à ciência e à tecnologia para conduzir ao permanente desenvolvimento de aptidões para a vida produtiva. $\mathrm{O}$ aluno matriculado ou egresso do ensino fundamental, médio e superior, bem como o trabalhador em geral, jovem ou adulto, contaria com a possibilidade de acesso à educação profissional. A educação profissional seria desenvolvida em articulação com o ensino regular ou por diferentes estratégias de educação continuada, em instituições especializadas ou no ambiente de trabalho. O conhecimento adquirido na educação profissional, inclusive no trabalho, poderia ser objeto de avaliação, reconhecimento e certificação para prosseguimento ou conclusão dos estudos. Além disso, ficou definido que os diplomas de cursos de educação profissional de nível médio, quando registrados, teriam validade nacional e que as escolas técnicas e profissionais, além dos seus cursos regulares, ofereceriam cursos especiais, abertos à comunidade, condicionada a matrícula à capacidade de aproveitamento e não necessariamente ao nível de escolaridade (BRASIL, 1996). 
integração com os diversos setores da sociedade e do setor produtivo (BRASIL, 1994). O art. $3^{\circ}$. desta lei estabeleceu a transformação de várias Escolas Técnicas Federais ${ }^{5}$ em Centros Federais de Educação Tecnológica (Cefets), cuja regulamentação definitiva somente ocorreu em 1997, com o decreto $\mathrm{n}^{\circ}$. $2.406^{6}$. Os primeiros Cefets foram criados em 1978 com a lei $\mathrm{n}^{\circ}$. 6.545/78, a partir da transformação das Escolas Técnicas Federais no Paraná, Minas Gerais e Rio de Janeiro. Essa lei também autorizou, além da implantação dos cursos de engenharia industrial e dos cursos técnicos de $2 .^{\circ}$ grau, cursos superiores de tecnologia (BRASIL, 1978).

A ampliação da transformação das Escolas Técnicas Federais em Cefets, associada à autonomia para a criação de cursos e ampliação de vagas nos níveis básico, técnico e tecnológico da Educação Profissional ${ }^{7}$, indica a tendência do legislador em facilitar a ampliação de vagas e a abertura de cursos na educação profissional. Quais seriam os motivos do governo brasileiro ao adotar esta política? Muitas evidências indicam a influência de pressões por parte de Organismos Internacionais sobre os rumos da educação brasileira.

Os Centros de Educação Tecnológica passaram a ter, ainda, a prerrogativa de suspender ou reduzir a oferta de vagas em seus cursos de nível tecnológico da educação profissional de modo a adequar-se às necessidades do mercado de trabalho. A legislação pretendeu estender aos Centros de Educação Tecnológica, inclusive os privados, alguma forma de suposta autonomia. Mais recentemente, com a lei 11.184/05, o Governo Lula transformou o Cefet-PR em Universidade Tecnológica Federal do Paraná, utilizando o artigo 52 da LDB, proporcionando um notável avanço para o ensino profissionalizante no país (BRASIL, 2005).

Considerando a necessidade de implementar o Programa de Reforma da Educação Profissional, os Ministérios da Educação e do Trabalho criaram, mediante a Portaria Interministerial $n^{\circ}$. 1.018/97, o Conselho Diretor do Programa de Expansão da Educação Profissional - Proep, para ser desenvolvido até 2003, dispondo de US\$500 milhões, dos quais US\$250 milhões foram empréstimos do Banco Interamericano de Desenvolvimento (BID), com igual contrapartida brasileira dos orçamentos do Ministério da Educação e do Fundo de Amparo ao Trabalhador (FAT), este ligado ao Ministério do Trabalho (BRASIL, 1997e). Esses recursos estão sendo aplicados para dotar os Centros de Educação Profissional de infra-estrutura, equipamentos e pessoal capacitado e adequar e atualizar

5 Criadas pela lei $\mathrm{n}^{\mathrm{o}}$. 3.552 , de 16 de fevereiro de 1959 e pela lei $\mathrm{n}^{\mathrm{o}}$. 8.670 , de 30 de junho de 1993.

6 Regulamenta a lei $n^{\circ} .8 .948$, de 8 de dezembro de 1994, e dá outras providências (BRASIL, 1997d).

7 Disposição contida no artigo $8^{\circ}$. do Decreto nº. 2.406, de 27 de novembro de 1997. 
currículos. A meta do Proep é triplicar em cinco anos a oferta do ensino profissional em todos os níveis para que o Brasil atinja uma situação parecida com a dos países mais desenvolvidos. O objetivo é dotar 200 Centros de Educação Profissional (70 federais, 60 estaduais e 70 comunitários) de infra-estrutura, equipamentos e pessoal (REVISTA, 1998).

Até 2000, o Proep possibilitou a construção, ampliação e modernização de 155 escolas de formação de trabalhadores no Brasil. Com isso, foram criadas condições de oferta de 200 mil novas vagas no ensino técnico, 700 mil no ensino profissional do nível básico e 23 mil do nível tecnológico, sendo que muitas dessas vagas estão sendo ofertadas por escolas do segmento comunitário, representado por entidades da sociedade civil organizada, que atuam na formação de trabalhadores (REVISTA, 2000). Além disso, alguns dos instrumentos legislativos, relacionados com a implementação da educação profissional, estimulam as instituições de ensino tecnológico a incrementar parcerias com o setor produtivo, visando ao aporte de recursos financeiros para atendimento de projetos institucionais.

Segundo a Revista de Educação Profissional do MEC (1998), a revolução da educação profissional brasileira é resultado da observação de modelos de sucesso de outros países, como Israel, Argentina e Austrália. Antes de chegar à formulação do projeto brasileiro, o MEC estudou três concepções básicas da relação entre o ensino geral e o profissionalizante. O primeiro modelo, chamado de dual, é praticado pela Alemanha, Suíça, Espanha, entre outros países, onde, a partir de um determinado estágio, o aluno tem que optar entre a formação acadêmica na universidade ou a formação profissionalizante de nível médio, sendo que as duas vertentes são inconciliáveis.

A segunda concepção também estabelece essa distinção. Entretanto, cria condições para que o estudante que optou pelo profissionalizante, também possa ingressar em um curso superior. Esse é o modelo predominante na maioria dos países, com destaque para França, Chile e Áustria, e foi o modelo que vigorou no Brasil até 1996. A recente tendência mundial e que foi adotada pelo Brasil, exige do trabalhador um conjunto de competências, habilidades e conhecimentos mais próximos da educação geral do que da educação mista. Os currículos vão traduzir o que o mundo do trabalho quer. O estagiário deve ter contato com o mercado de trabalho ao longo de todo o curso de formação e as escolas devem se aproximar das empresas e vice-versa, como já acontece no Canadá. É o paradigma da empregabilidade que se instala.

Entretanto, o Governo Lula, com o Decreto ${ }^{\circ}$. 5.154/04, possibilitou novamente a segunda concepção no país, ampliando as opções do ensino técnico para a população (BRASIL, 2004). 
Segundo Castro (1990), o desenvolvimento brasileiro até hoje se sustentou nas vantagens relativas de nossa mão-de-obra barata e não-qualificada e da abundância de matérias-primas, o que era compatível com uma população ignorante e uma pequena elite educada. Para o autor, isso terminou. A competitividade, a eficiência e a criatividade da população como um todo é agora indispensável num mundo onde a universalização da economia e da tecnologia é inevitável.

No que diz respeito ao ensino profissional, as diretrizes do Banco Mundial, a partir da década de 1970, tratam de estreitar os vínculos entre esse nível de ensino e as atividades econômicas, especialmente em relação às pequenas empresas do setor informal. O objetivo de desenvolvimento institucional ainda permanece como preocupação central, acrescentando-se aí a colaboração entre o setor público e privado como estratégia de base à meta de desenvolvimento de padrões de qualidade e de eficiência no treinamento profissional (FONSECA, 1995). No entanto, talvez pelo infortúnio da lei 5.692/71, a ênfase dos financiamentos do Banco Mundial desloca-se, na década de 1980, do ensino técnico de nível secundário para a alfabetização e a educação geral.

\section{A educação brasileira e o contexto institucional}

O contexto institucional brasileiro vem sendo marcadamente delineado, ao longo dos anos, por uma estrutura de poder que transcende o Estado Brasileiro. Conforme delimitou Faoro (1977), o estamento burocrático nacional vem se perpetuando no poder e executando fielmente determinações externas, independentemente da realidade vivenciada pela maioria da população brasileira.

Aproveitando a lição dos crítico-reprodutivistas, é preciso considerar uma instituição de ensino dentro do contexto social e político onde está inserida e, portanto, submetida a diversos determinismos. Mas também podemos redescobri-la como um espaço público que, não sendo o único agente possível de mudança, é um, dentre outros, nos quais a transformação pode ser pensada. Daí a importância da ação conjunta dos profissionais do ensino, bem como de alunos, pais e associações de diversos tipos, todos empenhados nos esclarecimentos dos objetivos a serem alcançados pela escola e na pressão exercida sobre os órgãos públicos para o cumprimento do que lhes compete (ARANHA, 1989).

É possível afirmar que essas tendências neoliberais vêm se alastrando pelo cenário educacional brasileiro desde a aprovação da lei $n^{\circ}$. 4.024/61. Para Gadotti (1991), sob pretexto da defesa da "liberdade de ensino", essa LDB abriu caminho para a exploração comercial do ensino, impedindo, na prática, o desenvolvimento da escola pública. 
Associadas às pressões coercitivas da legislação, existem também pressões sociais que impõem às organizações a necessidade por legitimação diante desse contexto. Essa é uma situação característica da falácia neoliberal, em que as propostas da "neo-reforma" educacional consideram o padrão de reformas neoliberais como única alternativa disponível; a associação entre educação e desenvolvimento (econômico ou social) é característica da visão funcionalliberal; a idéia de equidade é construída sob o enfoque estrito do desempenho individual, endossando a lógica da competição e uma concepção do homem econômico forjada no liberalismo; os princípios de equidade e democracia são considerados dependentes da ordem econômica; os atores sociais mais organizados são tratados como empecilhos à materialização da reforma; a noção de Estado incorporada nos diagnósticos para a crise é estática e atribui-lhe característica universal e, finalmente, não se manifesta nenhum tipo de inquietação com os efeitos perversos da ordem mundial centralizada no binômio globalização econômica/localismo na política (COSTA, 1995).

A tendência à homogeneização das instituições é preconizada pela Teoria Institucional (MEYER; ROWAN, 1977; SCOTT, 1995), em que toda a situação social que perdura no tempo, tem a tendência de ser institucionalizada, devido à necessidade de previsibilidade e controle social das ações rotineiras. Tal teoria atende e, de certa forma, é vinculada aos interesses da classe dominante. É a sociedade da regulação. Entretanto, a forma como esse processo de institucionalização é desencadeado não é percebido facilmente. A sutileza como as crenças e os valores sociais são moldados a partir dos interesses de uma elite dominante tem-se mostrado recorrente na história do país.

A corrente funcionalista, de cunho determinista, considera esse conjunto de valores e interesses como ferramenta para administrar, definindo a relação entre eventos culturais como estórias, ritos, linguagem, sagas e mitos, com aspectos como produtividade, rotatividade, entre outros; é visão utilitarista e objetiva, que acredita poder controlar e influenciar o desempenho das organizações. Sob a perspectiva funcionalista, as organizações são vistas como instrumentos sociais para a realização de tarefas, nas quais a cultura é tratada como uma variável. Evidencia-se que os mecanismos de dominação e formação de opinião neoliberais são predominantemente funcionalistas.

De acordo com Gadotti (1980), a tecnoburocracia não controla apenas os aparelhos do Estado e a organização (ALTHUSSER, 1983), como também impõe novas crenças e valores: sobrevaloriza o planejamento (controle) e o conhecimento técnico-profissional, a hierarquia, a ordem, as estruturas, a eficácia, a impessoalidade, a precisão, etc. Para a tecnoburocracia, a escola deve ser uma comunidade harmoniosa e imutável, em que os problemas precisam ser resolvidos técnica e administrativamente, e não pedagogicamente. É o advento 
da racionalidade instrumental na consecução das características burocráticas. Esta racionalidade refere-se a esferas de vida e a uma estrutura de dominação que adquiriu fronteiras específicas e delineadas somente com a industrialização, através da forma burocrática de dominação. Ela legitima um cálculo semelhante de meio-fim por referência a regras, leis ou regulamentos universalmente aplicados. Weber (1944) cita a dominação burocrática como formalmente racional porque a ação orientada para regras e estatutos predomina, assim como a seleção dos meios mais adequados pela aderência continuada a eles.

Quem domina no campo econômico tem poder para decidir o que é interessante que se torne de domínio público. Assim, os meios de comunicação funcionam como mecanismos de triagem de informações, como uma espécie de filtro por meio do qual se mantém o controle sobre o que é convenientemente divulgado para a grande maioria da população (ECO, 1970; PÊCHEUX, 1995). Por estarem diretamente atrelados ao poder, não há como os meios de comunicação estarem a favor dos interesses das massas (TONUS, 2000). Os efeitos de uma mídia manipulada podem ser tão aviltantes quanto foram os da censura no regime militar. Cria-se, portanto, o que Bordieu (1996) chama de linguagem autorizada, em que os instrumentos de controle fogem da figura de um indivíduo e passam a ser disseminados pela cultura estabelecida pela coletividade e pelas regras do sistema dinâmico, que não são fixas, mas modificadas sem cessar, de forma que quando algumas desaparecem outras começam a ser aplicadas, de acordo com os interesses dos grupos dominantes.

Segundo Hayek (1984), a liberdade de pensamento numa sociedade como a nossa é praticamente inexistente, pois as opiniões dos indivíduos são plasmadas pela propaganda, pela publicidade, pelo exemplo das classes dirigentes e por fatores conjunturais que obrigam o pensamento a se conformar a padrões estabelecidos e convenientes. "A aceitação da inevitabilidade conduz à concretização da realidade projetada [...]" (TONUS, 2000, p. 81), pois "o irrealizado irrompe no já estabelecido" (ORLANDI, 1999, p. 54).

\section{Possibilidades de pesquisas}

A problemática ora levantada pretende estimular a realização de pesquisas que busquem verificar como o contexto institucional vem afetando as transformações ocorridas na educação profissional brasileira, a partir da década de 1970 e que descrevam as principais transformações ocorridas no ensino profissionalizante e a relação entre as pressões contextuais e as transformações 
ocorridas no período em exame.

O trabalho científico necessita de um referencial metodológico coerente e consistente. A partir dos objetivos e do referencial teórico, algumas hipóteses foram formuladas, partindo-se do pressuposto de que o discurso autoritário ${ }^{8}$ vem prevalecendo no Brasil, desde o Golpe Militar de 1964:

- As pressões contextuais por ocasião da imposição da lei 5.692/71 não se diferenciam das pressões contextuais quando da aprovação da lei 9.394/96 e caracterizam-se como neoliberais;

- Os valores institucionalizados na sociedade são os mesmos nos dois contextos e justificam uma seqüência de objetivos do neoliberalismo;

- As pressões contextuais coercitivas e normativas vêm afetando significativamente as transformações ocorridas no ensino profissionalizante brasileiro.

Pesquisas dessa natureza caracterizam-se como estudos historiográficos (longitudinais), pois se propõem a investigar as categorias analíticas partindo de seus aspectos evolutivos, traçando a seqüência de eventos ao longo do tempo a partir de um momento pré-determinado. É descritiva, pois discorre sobre os acontecimentos e descobre seus fenômenos-chave e, além disso, é interpretativa ao sintetizar a informação recopilada para determinar tendências e generalizar seus significados (RICHARDSON et al., 1999).

Os procedimentos da pesquisa histórica são predominantemente qualitativos e buscam a compreensão dos fenômenos sociais ao longo do tempo. Segundo Richardson et al. (1999, p. 246), "a pesquisa histórica baseia-se em observações que não podem ser repetidas". De acordo com Triviños (1987), a pesquisa qualitativa possui as seguintes características: tem o ambiente natural como fonte direta dos dados e o pesquisador como instrumento-chave, é descritiva, preocupa-se com o processo e não simplesmente com os resultados e o produto, tende a analisar seus dados indutivamente e a preocupação central dessa abordagem é o significado.

Os dados disponíveis deverão ser examinados previamente para determinar se existe suficiente informação (corpus) que permita a realização da pesquisa, considerando o período da análise. Segundo Hockett (1955), a revisão crítica

8 O discurso autoritário é o que tende para a paráfrase e em que a polissemia é contida (procura-se impor um só sentido) (ORLANDI, 1996). Esse discurso não abre possibilidades para que o interlocutor interprete a seu modo a realidade, pois o sentido único já está nele constituído. 
dos dados reunidos é o passo mais importante na pesquisa histórica. Os dados utilizados pelo historiador consistem em formulações escritas carregadas de interpretações. Portanto, o investigador deve ser capaz de reconhecer a objetividade do fato, de modo que a informação reunida deva ser examinada rigorosamente para efetivar a sua exatidão.

Os dados devem ser coletados visando relacionar toda a informação disponível sobre os acontecimentos estudados. Para tanto, fontes e dados que contribuam para uma melhor análise dos acontecimentos devem ser investigados, como por exemplo, documentos que identifiquem a política econômica e educacional do Governo Brasileiro, no período considerado. Ocorrências que relacionem aspectos econômicos, culturais e educacionais, bem como análises estatísticas, dados em jornais, revistas, informações legislativas e outras que possam enriquecer a análise também devem ser levantadas.

Para Richardson et al. (1999), as fontes de dados históricos classificamse em:

Fontes primárias: são aquelas que tiveram uma relação direta com os fatos analisados, existindo um relato ou registro da experiência vivenciada, como por exemplo, uma fotografia ou uma gravação direta de um acontecimento, relatos escritos sobre fatos, transcrições oficiais de uma reunião, entre outros.

Fontes secundárias: são aquelas que não têm uma relação direta com o acontecimento registrado, senão por meio de algum elemento intermediário, como por exemplo, relatos de terceiros sobre um fato e entrevistas pessoais com participantes de um evento, distanciados consideravelmente da fonte primária.

A análise dos dados, pela natureza desse tipo de pesquisa, deve ser predominantemente descritivo-qualitativa. A utilização de fontes primárias e secundárias tem por objetivo a obtenção de dados confiáveis relacionados com as categorias analíticas investigadas, além de auxiliar a contextualização dos fatos, permitindo ao pesquisador interpretar e compor o cenário da educação profissional brasileira.

Recomenda-se a utilização da análise documental das diversas fontes primárias e secundárias e uma análise de congruência entre os contextos institucionais e os valores identificados no período considerado pela pesquisa. Segundo Bardin (1977), análise documental consiste em uma série de operações que visam a estudar e analisar um ou vários documentos para descobrir as circunstâncias sociais e econômicas com as quais podem estar relacionados. A análise de congruência, por sua vez, busca identificar convergência ou divergência entre os conjuntos de dados dos diferentes contextos institucionalizados e entre os valores dominantes, por ocasião das duas leis sancionadas, mediante comparação direta, concebendo ou não a similaridade dessas categorias analí- 
ticas, ao longo do tempo.

Dentre as técnicas utilizadas para a análise de conteúdo de documentos, indica-se a análise temática, considerada a mais adequada, pois se centra na observação de temas ou unidades de significação, cuja identificação demanda do pesquisador o conhecimento de critérios, geralmente sugeridos pela base teórica que norteia o trabalho. A análise temática consiste "em descobrir os núcleos de sentido que compõem a comunicação e cuja presença ou freqüência de aparição podem significar alguma coisa para o objetivo analítico escolhido" (BARDIN, 1977, p. 105).

A relação de influência entre o contexto institucional e as transformações ocorridas no ensino profissional brasileiro, deve ser, portanto, verificada mediante análise qualitativa que utiliza mapeamentos de relação a serem gerados em análise documental para identificar a existência de congruência.

\section{REFERÊNCIAS}

ALTHUSSER, L. Aparelhos ideológicos de Estado. Rio de Janeiro: Graal, 1983.

ARANHA, M. L. A. Filosofia da educação. São Paulo: Moderna, 1989.

BARDIN, L. Análise de conteúdo. Lisboa: Edições 70, 1977.

BENATTI, L. Ensino técnico é luxo, diz ministro. Folha de São Paulo, 9 abr. 1997. Folha Cotidiano, p. 3.

BOURDIEU, P. A economia das trocas lingüísticas. São Paulo: EDUSP, 1996.

BRASIL. Decreto n. 7.566, de 23 de setembro de 1909. Cria nas capitais dos Estados da República Escolas de Aprendizes e Artífices para o ensino profissional primário e gratuito. In: FONSECA, C. S. História do ensino industrial no Brasil. v. 1. Rio de Janeiro: Escola Técnica Nacional, p. 163, 1961.

BRASIL. Lei n. 5.692, de 11 de agosto de 1971. Fixa diretrizes e bases para o ensino de $1 .^{\circ}$ e $2{ }^{\circ}$ graus e dá outras providências. Diário Oficial da União, 12 ago. 1971.

BRASIL. Lei n. 6.545, de 4 de julho de 1978. Dispõe sobre a transformação das Escolas Técnicas Federais de Minas Gerais, do Paraná e Celso Suckow da Fonseca em Centros Federais de Educação Tecnológica. Diário Oficial da União, 4 jul. 1978.

BRASIL. Lei n. 8948 de 8 de dezembro de 1994. Dispõe sobre a instituição do Sistema 
Nacional de Educação Tecnológica e dá outras providências. Disponível em <www. leidireto.com.br/lei8948.html>

BRASIL. Lei n. 9.394, de 20 de dezembro de 1996. Estabelece as diretrizes e bases da educação nacional. Diário Oficial da União, seção 1, p. 27.839, 23 dez. 1996.

BRASIL. Decreto n. 2.207, de 15 de abril de 1997a. Regulamenta, para o Sistema Federal de Ensino, as disposições contidas nos art. 19, 20, 45, 46 e $\S 1$ 1. $^{\circ}, 52, \S$ único, 54 e 88 da Lei n. 9.394, de 20 de dezembro de 1996. In: MINISTÉRIO DA EDUCAÇÃO. Programa de Legislação Educacional Integrada. Disponível em: <http://prolei.cibec. inep.gov.br/navega/informa.asp?Tip=18\&Ttip $=$ Decreto $>$.

BRASIL. Decreto n. 2.208, de 17 de abril de 1997b. Regulamenta o parágrafo 2. ${ }^{\circ}$ do artigo 36 e os artigos 39 a 42 referentes à Educação Profissional da Lei n. 9.394, de 20 de dezembro de 1996. In: MINISTÉRIO DA EDUCAÇÃO. Legislação educacional. Disponível em: <http://www.mec.gov.br/ semtec/educprof/Legislacomum.shtm>.

BRASIL. Ministério de Estado da Educação. Portaria n. 646, de 14 de maio de 1997. Regulamenta a implantação do disposto nos artigos 39 a 42 da lei n. 9.394/96 e dá outras providências. Diário Oficial da União, n. 91, Brasília, 15 maio 1997c.

BRASIL. Decreto n. 2.406, de 27 de novembro de 1997d. Regulamenta a Lei n. 8.948, de 8 de dezembro de 1994 e dá outras providências. In: MINISTÉRIO DA EDUCAÇÃO. Programa de Legislação Educacional Integrada. Disponível em: <http://prolei.cibec. inep.gov.br/navega/informa.asp?Tip $=18 \&$ Ttip=Decreto $>$.

BRASIL. Portaria Interministerial n. 1.018, de 11 de setembro de 1997e. Cria o Conselho Diretor do Programa de Reforma da Educação Profissional - PROEP. In: MINISTÉRIO DA EDUCAÇÃO. Legislação educacional. Disponível em: $<$ http://www.mec.gov.br/semtec/educprof/Legislacomum.shtm>.

BRASIL. Decreto n. 5.154, de 23 de julho de 2004. Regulamenta o $\S 2^{\circ}$ do art. 36 e os arts. 39 a 41 da Lei n. 9.394, de 20 de dezembro de 1996, que estabelece as diretrizes e bases da educação nacional, e dá outras providências. In: MINISTÉRIO DA EDUCAÇÃO. Programa de Legislação Educacional Integrada. Disponível em: $<$ http://portal.mec.gov.br/setec/arquivos/pdf/dec5154.pdf $>$.

BRASIL. Lei n. 11.184, de 07 de outubro de 2005. Dispõe sobre a transformação do Centro Federal de Educação Tecnológica do Paraná em Universidade Tecnológica Federal do Paraná e dá outras providências. Diário Oficial da União, 10 out. 2005.

CASTRO, C. M. Entrevista. O Globo, Rio de Janeiro, 5 ago. 1990. 
COSTA, M. A educação em tempos de conservadorismo. In: APPLE, M. W. et al. (Org.). Pedagogia da exclusão: crítica ao neoliberalismo em educação. Petrópolis: Vozes, p. 43-76, 1995.

ECO, U. Apocalípticos e integrados. 2. ed. São Paulo: Perspectiva, 1970.

FAORO, R. Os donos do poder. São Paulo: Globo, 1977.

FOUCAULT, M. A arqueologia do saber. 5. ed. Rio de Janeiro: Forense Universitária, 1997.

FONSECA, C. S. História do ensino industrial no Brasil. v. 1. Rio de Janeiro: Escola Técnica Nacional, 1961.

FONSECA, M. O Banco Mundial e a Educação: reflexões sobre o caso brasileiro. In: APPLE, M. W. et al. (Org.). Pedagogia da exclusão: crítica ao neoliberalismo em educação. Petrópolis: Vozes, p. 169-195, 1995.

GADOTTI, M. Educação e poder: introdução à pedagogia do conflito. São Paulo: Cortez/Autores Associados, 1980.

. Pensamento pedagógico brasileiro. 4. ed. São Paulo: Ática, 1991.

HAYEK, F. A. O caminho da servidão. Rio de Janeiro: Instituto Liberal, 1984.

HOCKETT, H. C. The critical method in historical research and writing. New York: Macmillan, 1955.

HORTA, J. S. B. Planejamento educacional. In: SAVIANI, D. et al. Filosofia da educação brasileira. Rio de Janeiro: Civilização Brasileira, 1998.

MENDES, D. T. (Coord.). Prefácio. In: SAVIANI, D. et al. Filosofia da educação brasileira. Rio de Janeiro: Civilização Brasileira, 1998.

MEYER, J. W.; ROWAN, B. Institutional organizations: formal structure as myth and ceremony. American Journal of Sociology, v. 83, n. 2, p. 340-363, 1977.

MINISTÉRIO DA EDUCAÇÃO. Programa de Expansão da Educação Profissional. Proep prepara aluno para o mercado de trabalho. Disponível em: $<\mathrm{http}: / /$ www.mec. gov.br/semtec/proep/oqueproe.shtm>. Acesso em: 20/3/2002.

ORLANDI, E. Discurso e leitura. 3. ed. Campinas: Editora da UNICAMP, 1996. . Análise de discurso: princípios \& procedimentos. Campinas: Pontes, 1999.

PÊCHEUX, M. Semântica e discurso: uma crítica à afirmação do óbvio. Campinas: Editora da UNICAMP, 1995. 
QUELUZ, G. L. Concepções de ensino técnico na República Velha: estudo dos casos da Escola de Aprendizes Artífices do Paraná, do Instituto Técnico Profissional de Porto Alegre e do Serviço de Remodelação do Ensino Profissional Técnico (1909-1930). São Paulo, 2000. 274 f. Tese (Doutorado em Comunicação e Semiótica) - Centro Simão Mathias de Estudos em História da Ciência, Pontifícia Universidade Católica de São Paulo.

REVISTA de Educação Profissional. Educação profissional: formação e qualificação para o mercado de trabalho. Brasília: Ministério da Educação/PROEP. 1998. Disponível em: <http://www.mec.gov.br/semtec/educprof/revi98.pdf $>$. Acesso em: 20/3/2002.

REVISTA de Educação Profissional. Brasília: Ministério da Educação/Proep. 2000. Disponível em: <http://www.mec.gov.br/semtec/educprof/revista3.pdf > . Acesso em: 20/3/2002.

RIBEIRO, D. Nossa escola é uma calamidade. Rio de Janeiro: Salamandra, 1984.

RICHARDSON, R. J. et al. Pesquisa social: métodos e técnicas. 3. ed. São Paulo: Atlas, 1999.

SCOTT, W. R. Institutions and organizations. Thousand Oaks: Sage Publications Inc. 1995.

TONUS, L. H. A formação ideológica neoliberal em textos da Revista Veja que abordam a educação e as escolas brasileiras. Marília, 2000. 176 f. Dissertação (Mestrado em Educação) - Universidade Estadual Paulista, Campus de Marília.

TRIVIÑOS, A. N. S. Introdução à pesquisa em ciências sociais: a pesquisa qualitativa em educação. São Paulo: Atlas, 1987.

WEBER, M. Economía y sociedad. México: Fondo de Cultura Económica, 1944.

Texto recebido em 30 de março de 2006.

Texto aprovado em 13 de junho de 2006. 